Journal of Advanced Research in Fluid Mechanics and Thermal Sciences

Journal homepage: www.akademiabaru.com/arfmts.html ISSN: $2289-7879$

\title{
Quantifying Heat Losses in Micro Combustor with Wire Mesh Using Numerical Simulation
}

\author{
Fudhail Abdul Munir ${ }^{1,2,}{ }^{*}$, Nurfarah Diana Mohd Ridzuan Tan ${ }^{2, *}$, Masato Mikami ${ }^{3}$, Musthafah Mohd \\ Tahir $^{2}$ \\ 1 Centre for Advanced Research on Energy (CARe), Universiti Teknikal Melaka Malaysia, 76100 Durian Tunggal Melaka, Malaysia \\ 2 Faculty of Mechanical Engineering, Universiti Teknikal Melaka Malaysia, 76100 Durian Tunggal, Melaka, Malaysia \\ 3 Faculty of Mechanical Engineering, Yamaguchi University, 755-0053 Ube Yamaguchi, Japan
}

\section{ARTICLE INFO ABSTRACT}

\section{Article history:}

Received 16 December 2019 Received in revised form 25 February 2020

Accepted 25 February 2020

Available online 24 April 2020

\begin{abstract}
Micro power generation system is a field of study that has come into interest by many researchers due to the strong demands for low weight and long-life power sources of electronic devices. These has led to the increasement of meso and micro-scale combustion investigations. In order to fully understand more on this field of study, a numerical stimulation is utilized to investigate the effect of heat recirculation on the blowout limit for micro combustion. Four different combination of tube combustors is used to investigate their blowout limit such as quartz-brass tube combustion combination for unburned-burned region of micro combustor tube. The combination of tube combustors is then investigated using three-dimensional (3D) numerical simulation. The results suggested that by utilizing brass tube on either region of unburned or burned tube is able to improve the value of heat conducted on inner wall of via inner wall of the tube greatly. Due to the conductivity of brass tube is much larger than quartz tube, the improvement is expected.
\end{abstract}

Keywords:

Heat recirculation; blowout limit; micro combustion

Copyright @ 2020 PENERBIT AKADEMIA BARU - All rights reserved

\section{Introduction}

Micro power generation for the field of micro-scale combustion has attracted many researchers in increasing the effort of studying the possible usage of such power source. To focus on the potential of using micro combustion as power sources, there must be studies on analyzing the effects of many different variables on the micro combustion. Flame stabilization had been proven to be achievable in narrow spaces [12], yet the sustainability of such flame is extremely difficult due to the large surface to volume ratio of the micro-scale combustor [11]. This results to flame instability as smaller

\footnotetext{
* Corresponding author.

E-mail address: fudhail@utem.edu.my (Fudhail Abdul Munir)

* Corresponding author.

E-mail address: ndianatan96@gmail.com (Nurfarah Diana Mohd Ridzuan Tan)
}

https://doi.org/10.37934/arfmts.70.1.3745 
combustion channels suffers from thermal quenching which then influences the blowout limit of the combustion [5,6].

Flame stabilization is essential in meso and micro channel combustors. The experiments on micro combustion has revealed several characteristics of flames that are of importance in accordance to variables and to overcome these weaknesses, several strategies such as the flame stabilization in micro-scale combustors with wire mesh [14,15], flame stabilization with flame holder $[10,22,24]$ and the studies of different fuel-air mixture $[20,21]$ were conducted. Not only gaseous fuels were used, liquid fuels were also introduced and utilized in search for better fuel consumption. Heat recirculation in combustion is a method that is widely recognized as a way to enhance the stability of flame and can distribute temperature effectively. According to the paper Tang et al., [18] and Tang et al., [19], the presence of heat recirculation gives a large impact on stabilization of flame and temperature distribution. Besides, the study of inner and outer heat recirculation done by Bagheri and Hosseini [3] has concluded that while inner heat recirculation (IHR) distinctly improve flame characteristics and flame stabilization, outer heat recirculation (OHR) presents greater range emitter efficiencies. Although heat recirculation gives positive effect on combustion, the combustion experiment itself is not easy to be examined and experimental items may not be able to be obtained easily.

Thus, simulation approach is performed to substitute the actual experimentation. Numerical simulation approach is recently gaining more popularity to explore on the feasibility of combustion in meso and micro-scale combustion chamber. With numerical simulation, any new design of micro combustors can be reproduced and optimized after analyzing the simulation results. Computational Fluid Dynamics (CFD) has been used in the last two decades for numerical investigation on flame propagation and heat characteristics of combustion. Commercial software was utilized to study combustion fundamentals of gaseous fuels like propane and methane in micro combustors. For example, the characteristics of burner dimensions, external heat losses and effect of wall conductivity in meso-scale burners were employed using FLUENT software [17]. Recent numerical works has also given new ideas of blowout limits in different condition like in high pressure conditions [1], in preheating channels [23] and on the planar combustors [4]. Concerning the dimension of numerical simulation, two-dimensional (2-D) numerical simulation is unable to present the conductive heat transfer from a flame holder to the outer wall of combustor.

In this research, a three-dimensional (3D) numerical simulation of the effect of heat recirculation on blowout limit in micro-scale combustion is presented. Since conductive heat transfer from the wire mesh to the outer wall of combustor is needed to be presented, a 3D numerical simulation is performed instead of 2D simulation. The effect of heat recirculation on blowout limit is investigated. The blowout limit for each combination of quartz-brass tube for unburned-burned region are determined and comparisons are made based on the results of simulation. The main purpose of this study is to study the effect of heat recirculation on blowout limit for micro combustion.

\section{Numerical Setup}

A 3-D steady-state numerical simulation model of micro combustor with wire mesh was executed using the software ANSYS Release 14.0 with Fluent 6.3 [2]. The 3-D numerical model was developed primarily to analyze the heat recirculation flow within the combustor channel. The size of combustor is replicated based on the paper by Munir and Mikami [13] where the length of tube combustor is $40.2 \mathrm{~mm}$. The combustor has an inner diameter of $3.5 \mathrm{~mm}$ and wall thickness of $0.7 \mathrm{~mm}$.

The model has two different region that is separated by a stainless-steel wire mesh which is called the unburned and burned gas region. The wire mesh is set to $10 \mathrm{~mm}$ apart from the outlet burned region tube and is $30 \mathrm{~mm}$ from the center of combustor inlet. The distance is set to $30 \mathrm{~mm}$ for the 
flow to fully developed before going through the wire mesh. Based on Karagiannidis et al., [7], the typical value of $k$ for stainless-steel is $20 \mathrm{~W} / \mathrm{m} / \mathrm{K}$ which is set in this research for the wall thermal conductivity $(k)$ value on the wire mesh for conductive heat transfer. A set amount $0.28 \mathrm{~mm}$ square holes were drawn onto the wire mesh to allow fluids to pass through it. Propane-air mixture is utilized as the fuel for this research. Figure 1 illustrates the working model for the micro-scale combustor.

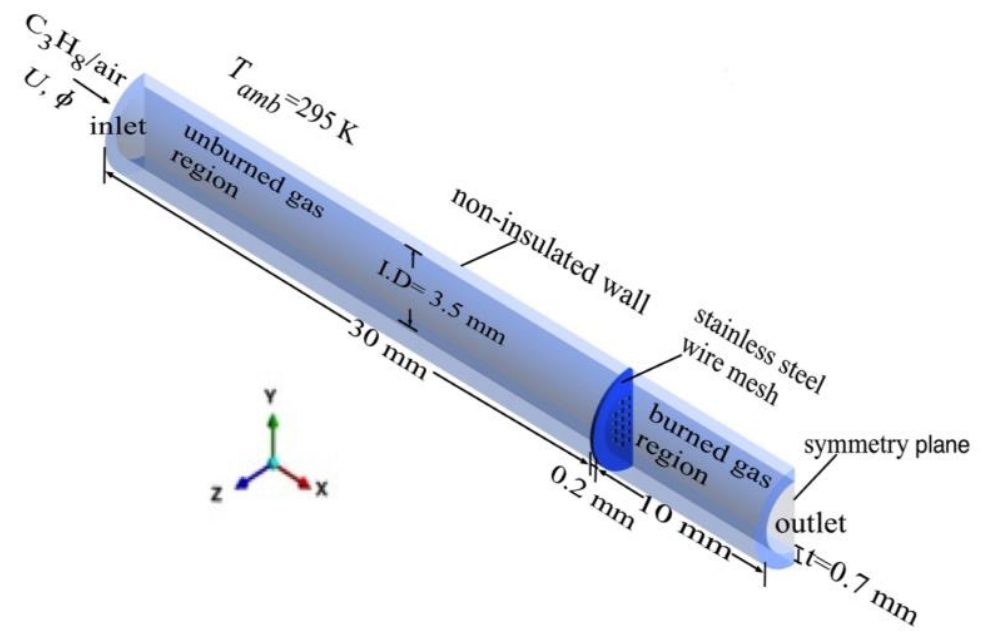

Fig. 1. 3-D numerical model of micro-scale combustor (Figure size is not to scale) [13]

For this research, Dufour, effects of gas radiation and work done by viscous and pressure force are assumed to be negligible. This is because the research done by Norton and Vlachos [16] shows that the gas phase radiation does not give much impact on the combustion reactions. For the gas density, ideal gas law is assumed. Besides, a piecewise-polynomial fit of temperature is used to calculate the specific heat for all the species. Whereas mixing law and kinetic theory are used to calculate the specific heat and thermal diffusion coefficient of the gas-fuel mixture. A reduced onestep propane combustion with five species is utilized as the combustion chemistry [8], where the affected species are $\mathrm{C}_{3} \mathrm{H}_{8}, \mathrm{O}_{2}, \mathrm{~N}_{2}, \mathrm{CO}_{2}$ and $\mathrm{H}_{2} \mathrm{O}$. the utilized combustion chemistry is as followed,

$$
\mathrm{C}_{3} \mathrm{H}_{8}+5 \mathrm{O}_{2} \rightarrow 3 \mathrm{CO}_{2}+4 \mathrm{H}_{2} \mathrm{O}
$$

In order to perform simulations, a comprehensive kinetic mechanism is necessary to study the stabilization of flame mechanism in micro-scale combustor, where the single step mechanism is sufficient. The employment of high grid concentrations is done using non-uniform grid element size in the area surrounding the wire mesh. The elements are totaled to a number of 42548 and applied for all cases. The execution of grid dependent test was done, and the results are such that larger number of elements has no significant numerical advantage.

In this work, boundary conditions are employed using similar conditions that was done by Li et al., [9] and applying no-slip boundary type condition between the interface of fluid and solid wall. Fourier's law is utilized to calculate the heat flux of this interface. Given that the heat transfer per unit area by means of convection at the outer surface of the tube combustor such that;

$q_{\text {loss }}=h_{\text {conc }}\left(T_{\text {wall }}-T_{a m b}\right)+\varepsilon \sigma\left(T_{w a l l}^{4}-T_{a m b}^{4}\right)$ 
where convective heat transfer coefficient is represented by $h$, wall temperature of combustor is $T_{\text {wall }}$ and ambient temperature is $T_{a m b}$. Initially, the value of ambient temperature $\left(T_{a m b}\right)$ is $296 \mathrm{~K}$. the convective heat transfer coefficient $(h)$ is set to a constant $4 \mathrm{~W} / \mathrm{m}^{2} \mathrm{~K}$, representing weak natural convection [9]. For the outer wall and wire mesh external emissivity $(\varepsilon)$, it is fixed at 0.90 and 0.70 , correspondingly. Meanwhile, the value $5.67 \times 10^{-8} \mathrm{~W} / \mathrm{m}^{2} \mathrm{~K}^{4}$ is set for Stefan-Boltzman constant $(\sigma)$. The right and left wall edge of the micro combustor is equipped with thermal insulation (zero heat flux boundary) whereas for a typical value of $k$ for quartz tube, the $k$ value is fixed to $1.6 \mathrm{~W} / \mathrm{m} / \mathrm{K}$. A fixed pressure inlet is applied to the outlet boundary condition. At z-plane of origin, a symmetrical boundary condition is determined in order for the half domain to be calculated. By utilizing data from Kutz [8] and ANSYS ${ }^{\circledR}$ Academic Research [2], the thermodynamic properties and gas transport data can be replicated.

At the combustor's inlet, a flat velocity profile with laminar flow of $U$ is applied. The feed temperature at the inlet is initially set to $295 \mathrm{~K}$ while no application of swirl flow velocity is done. At first, the $U$ value is fixed at $0.20 \mathrm{~m} / \mathrm{s}$ and equivalent ratio $(\phi)$ is set to 1 in order start combustion of the propane-air mixture. In step one, "cold flow" technique is applied where momentum and continuity equation is first solved. Energy and species equations are calculated and solved after the first step by defining an area of high temperature as patch zone. The location of the patch zone is 2.5 $\mathrm{mm}$ distance to the outlet and cannot be set too near to the outlet as ignition process can be affected negatively due to reverse gas flow. In the patch zone, $1500 \mathrm{~K}$ temperature is employed which is highly sufficient in ensuring that the propane-air mixture is able to be ignited. During ignition, the flame will propagate upstream and slowly stabilized close to the wire mesh. The value of $U$ steadily increases to find the blowout limit range with an interval of $0.05 \mathrm{~m} / \mathrm{s}$. The process will start all over again by applying the previous value of $U$ if the new $U$ value causes propagation of flame to the outlet. The interval will decrease to $0.01 \mathrm{~m} / \mathrm{s}$ until blowout phenomena occurs. Once the blowout phenomena happen, the blowout limit for the experiment will consider the maximum value of $U$ before the occurrence of the blowout phenomena.

Figure 2 demonstrates the supply of heat in the micro combustor for a near blowout phenomena. The designation of terms in the figure are as below:

$Q_{c 1}=$ heat conducted via the inner wall of the burned gas region

$Q_{c 2}=$ heat conducted via the inner wall of the unburned gas region

$\mathrm{Q}_{\mathrm{RU}}=$ heat recirculated to the unburned gas region

$\mathrm{Q}_{\mathrm{RM}}=$ heat recirculated to the wire mesh

$Q_{L B}=$ heat loss from the outer wall of the burned gas region to the ambient

$Q_{L M}=$ heat loss from the outer wall of the wire mesh to the ambient

$Q_{L U}=$ heat loss from the outer wall of the unburned gas region to the ambient

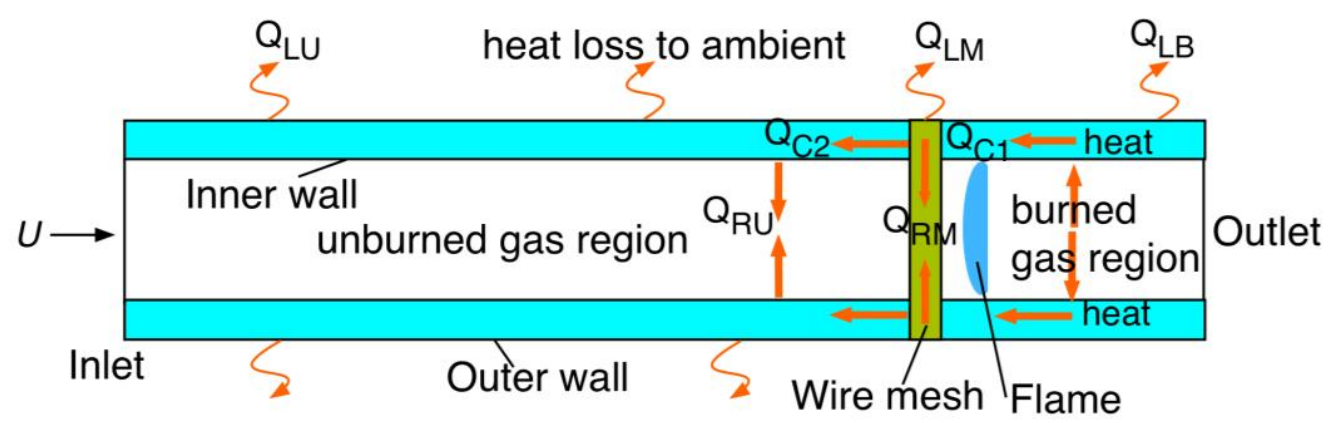

Fig. 2. Heat recirculated in the combustor near blowout conditions 


\section{Results and Discussion}

Higher flow velocity $(U)$ causes the behaviour of wire mesh thermal path to be reversed. This is due to flame position varies according to $U$. the lower the value of $U$, the nearer the flame is to the wire mesh. However, the higher the value of $U$, the more displaced the flame is from the wire mesh. The flame position is likely to be determined via numerical simulation as shown in Figure 3 where at $U=30 \mathrm{~cm} / \mathrm{s}$, the position of flame is at $0.43 \mathrm{~mm}$ away from the wire mesh. Heat recirculation happens when the heat from burned gas region is circulating through inner wall of the burned region towards the wire mesh. While Table 1 depicts the values of blowout limit range for four different tube combustor combination. The numerical simulation results show that with the use of brass tube at the burned gas region, the overall blowout limit value increases significantly.

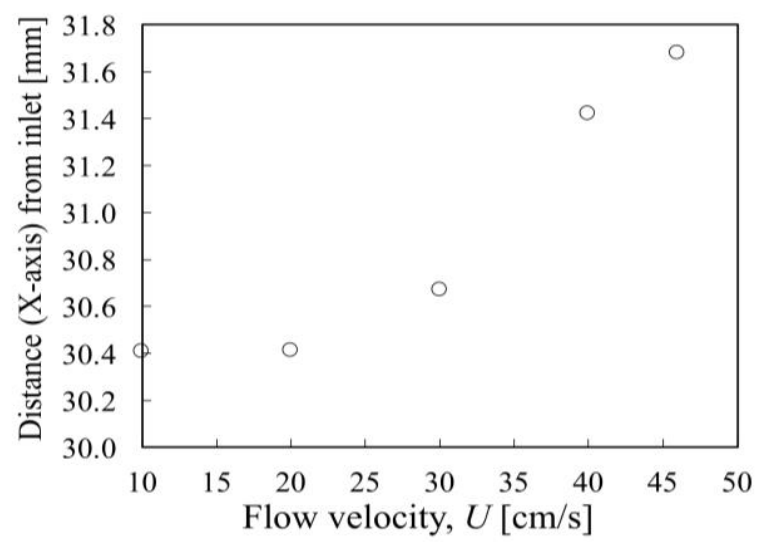

Fig. 3. Flame displacement for varies value of flow velocity $U$ at $\phi=1.0$ for quartz-quartz tube combustor

\section{Table 1}

Blowout limits for different tube combustors (from 3-D simulation)

\begin{tabular}{ll}
\hline Type of combustor & Blowout limits [cm/s] \\
\hline Quartz-quartz tube & 46 \\
Quartz-brass tube & 79 \\
Brass-quartz tube & 37 \\
Brass-brass tube & 69 \\
\hline
\end{tabular}

Firstly, once the unburned gas enters the inlet, the heat from burned region circulates to the unburned gas region $\left(Q_{R U}\right)$ which then allows the unburned gas to be pre heated by recirculated heat. Further into the chamber, the gas is again heated by the recirculated heat through the wire mesh $\left(Q_{R M}\right)$. So, $Q_{R U}$ and $Q_{R M}$ values plays a significant role to signify the amount of heat recirculated to pre-heat unburned gas. These values cause the increment of gas temperature prior to combustion. The energy balance for every boundary is calculated using the FLUENT software. Figure 4 shows the results produced for $Q_{R U}$ and $Q_{R M}$ for four different combustor tube combinations. $Q_{R M}$ in negative value only occurs when there is a low flow velocity which illustrates the flow of heat from the wire mesh center to the outer wall. At this point, the wire mesh functions as a flame inhibitor. When quartz tube is used in the unburned region as depicted in Figure 4(a) and Figure 4(b), the blowout limit is affected by the significant role played by the wire mesh as heat is recirculated to the unburned gas $\left(Q_{R M}\right)$ during the near blowout conditions. Thus, at higher flow velocity, the wire mesh functions as flame enhancer. However, when brass tube is used in the unburned region as shown in Figure 4(c) 
and Figure 4(d), the wire mesh is less likely to play an important role in recirculating the heat. In this condition, the inner wall of combustor has a more essential role in recirculating heat to the unburned gas $\left(Q_{R U}\right)$.
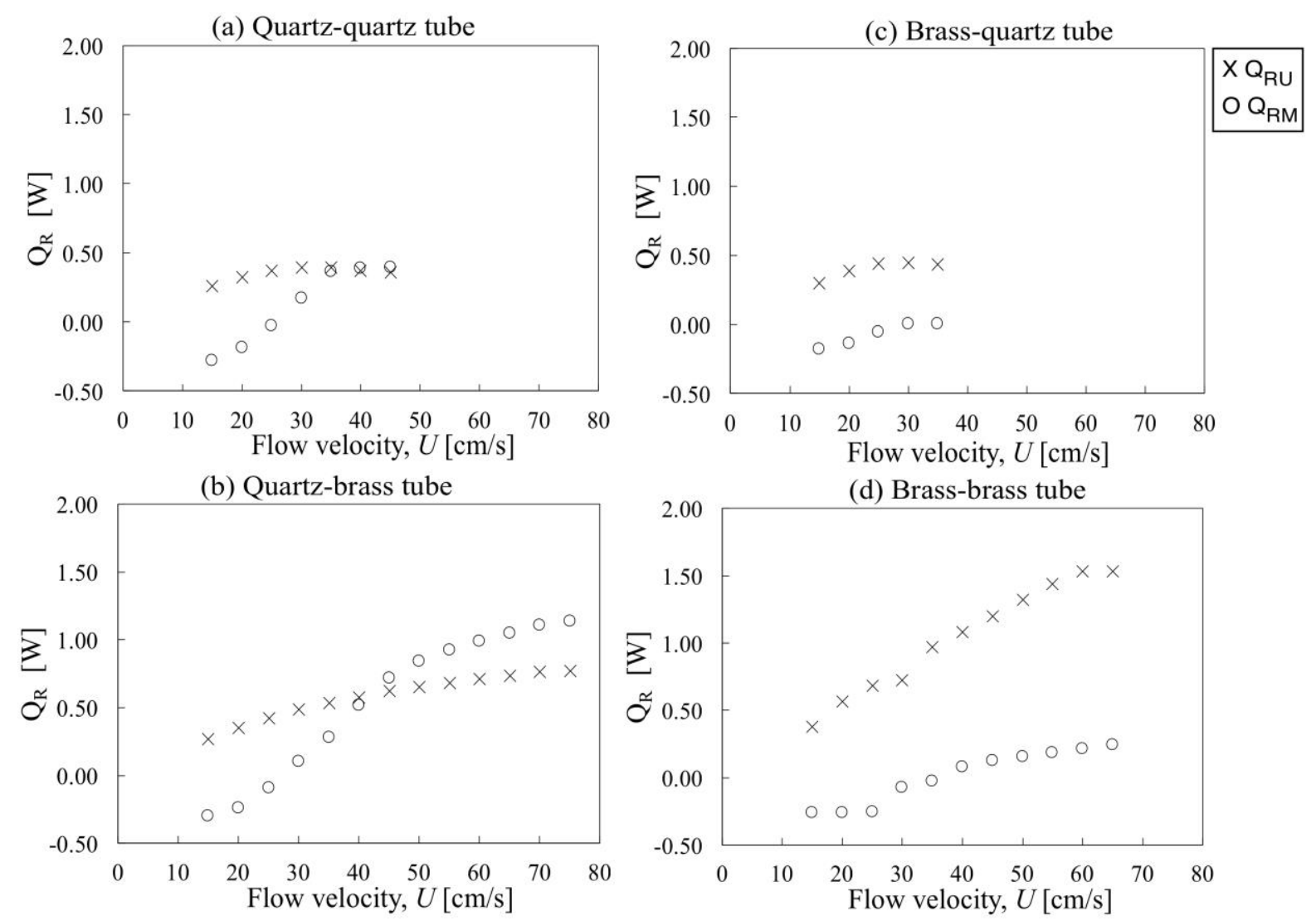

Fig. 4. Values of $Q_{R U}$ and $Q_{R M}$ with different flow velocities for each of combustor

$\mathrm{Q}_{\mathrm{RU}}$ and $\mathrm{Q}_{\mathrm{RM}}$ values were then plotted on together on a graph for the four different tube combustor combination. The comparisons are shown clearly in Figure 5 . It can be seen that the usage of brass tube in burned gas region drastically increases the value of recirculated heat $\left(Q_{R U}+Q_{R M}\right)$ to the unburned gas. In Figure 5(d), the percentage of heat release rate (HRR) that is being recirculated to the unburned gas region is up to $19 \%$ for the tube combustor combination of brass-brass and quartz-brass tube combustor. It is considered a high value for combustors with wire mesh.

Primarily, the solid walls of the tube combustor conduct heat from the burned gas region when the flow velocity $(U)$ is high. The heat conducted is represented as $Q_{c 1}$ and $Q_{c 2}$ which their values are directly proportional to the wall thermal conductivity $(k)$ of the tube. Two equations were formed to define $Q_{c 1}$ and $Q_{c 2}$ values. The following are the equations;

$Q_{C 1}=Q_{C 2}+Q_{R M}+Q_{L M}$

$\mathrm{Q}_{\mathrm{C} 2}=\mathrm{Q}_{\mathrm{RU}}+\mathrm{Q}_{\mathrm{LU}}$

$Q_{C 1}$ and $Q_{C 2}$ can be calculated using the created equation as the values of $Q_{R M}, Q_{L M}, Q_{R U}$ and $Q_{L U}$ were collected from the simulation using FLUENT software. Figure 6 shows the result of $Q_{c 1}$ and $Q_{c 2}$ values with varied flow velocities for the four different combustors. The result proves that when brass tube is utilized in either unburned or burned gas region, the values of $Q_{c 1}$ and $Q_{c 2}$ enhances 
significantly. This improvement in values are expected due to brass tube is known to have better wall thermal conductivity compared to quartz tube.
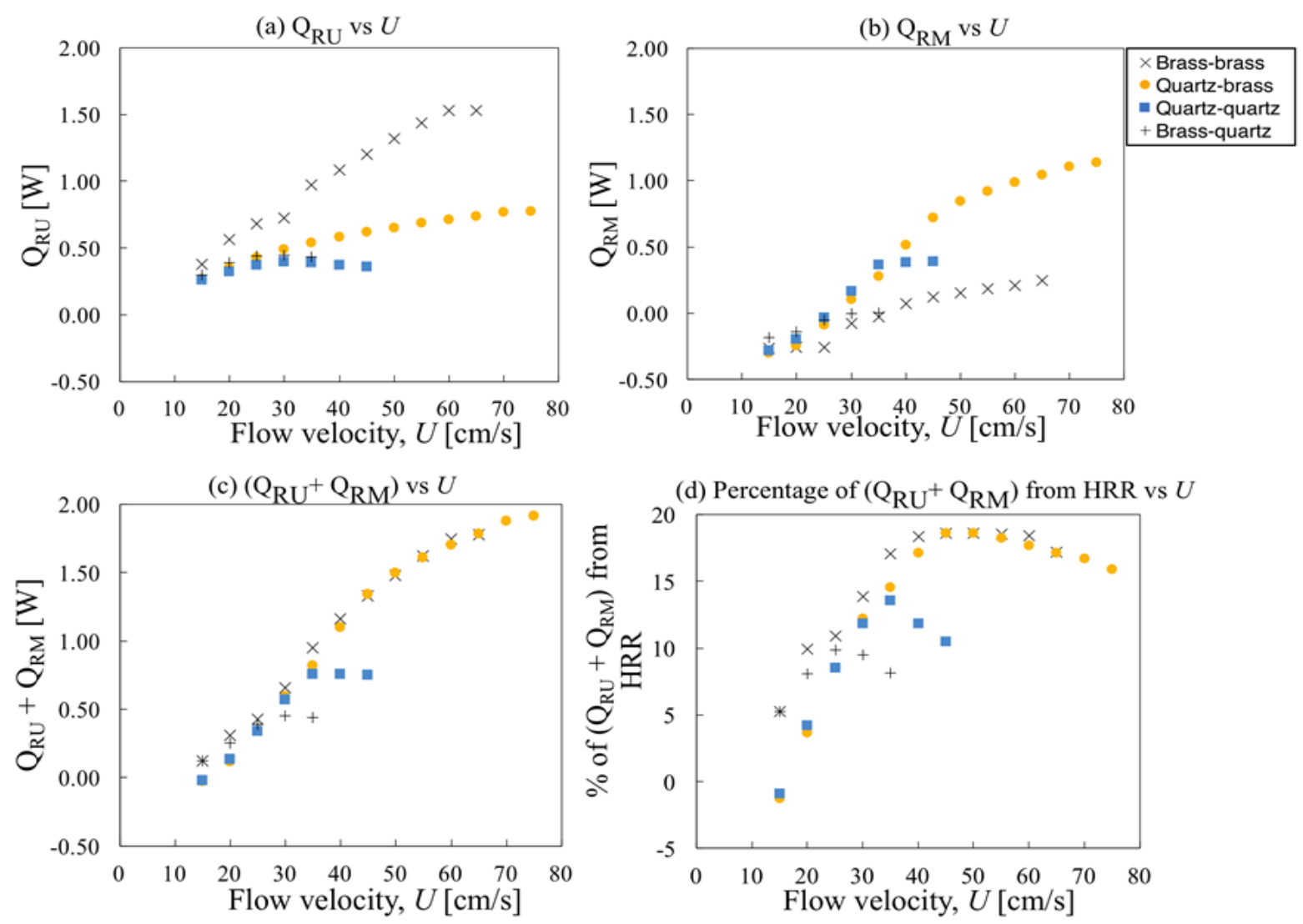

Fig. 5. $Q_{R U}$ and $Q_{R M}$ values for different flow velocities for the four different tube combustor combination

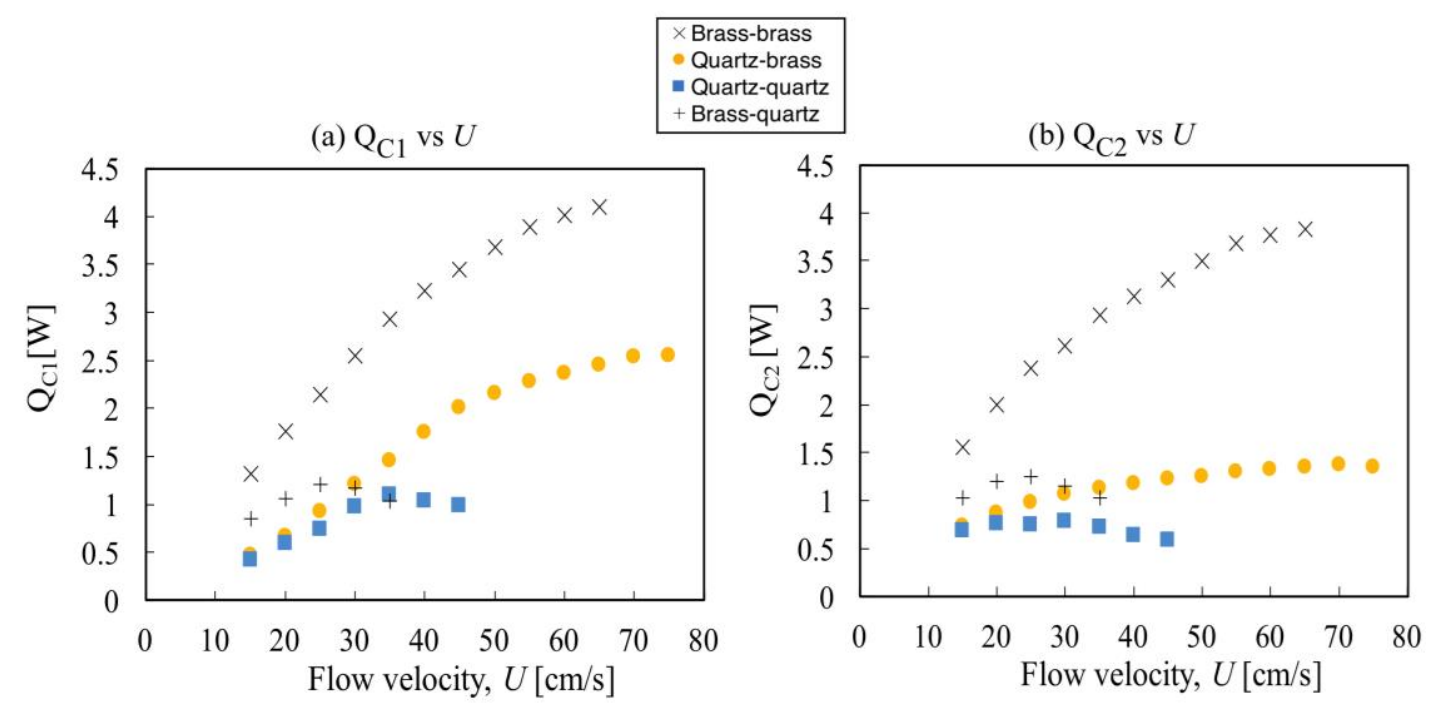

Fig. 6. Values of $Q_{c 1}$ and $Q_{c 2}$ with different flow velocities for each of combustor 


\section{Conclusions}

The simulation of three-dimensional (3D) model for micro scale combustion of propane-air fuel with stainless steel wire-mesh has been successfully accomplished. The simulation demonstrated clearly that at low flow velocity, the flames are much nearer towards the wire mesh whereas at higher flow velocity, there are flame displacement causing the flame to be further away from the wire mesh while keeping the flame relatively stable. At low flow velocity where flame is much nearer to the wire mesh. The heat flows from wire mesh to the outer wall causing the wire mesh to act as inhibitor. Meanwhile, at high flow velocity, the wire mesh does not play a significant role as the flame is further away from the wire mesh, which then causing the wire mesh to act as flame enhancer. Through the numerical simulations, it is proven that by utilizing brass tube at either unburned or burned gas region, the blowout limit of the flame in micro combustors dramatically increases.

\section{Acknowledgement}

This study was funded by a grant from Ministry of Higher Education of Malaysia (FRGS Grant FRGS/2018/FKM-CARE/F00370). Authors are thankful to Universiti Teknikal Malaysia Melaka (UTeM) and Yamaguchi University for sponsoring this research activity.

\section{References}

[1] Akhtar, Saad, Stefano Piffaretti, and Tariq Shamim. "Numerical investigation of flame structure and blowout limit for lean premixed turbulent methane-air flames under high pressure conditions." Applied Energy 228 (2018): 2132.

https://doi.org/10.1016/j.apenergy.2018.06.055

[2] ANSYS $^{\circledR}$ Academic Research. "Ansys Fluent." Canonsburg, ANSYS, Inc., 2012.

[3] Bagheri, Ghobad, and Seyed Ehsan Hosseini. "Impacts of inner/outer reactor heat recirculation on the characteristic of micro-scale combustion system." Energy Conversion and Management 105 (2015): 45-53. https://doi.org/10.1016/j.enconman.2015.07.056

[4] Cai, Tao, Aikun Tang, Dan Zhao, Chen Zhou, and Qiuhan Huang. "Experimental observation and numerical study on flame structures, blowout limit and radiant efficiency of premixed methane/air in micro-scale planar combustors." Applied Thermal Engineering 158 (2019): 113810. https://doi.org/10.1016/j.applthermaleng.2019.113810

[5] Chou, S. K., W. M. Yang, K. J. Chua, J. Li, and K. L. Zhang. "Development of micro power generators-a review." Applied Energy 88, no. 1 (2011): 1-16.

https://doi.org/10.1016/j.apenergy.2010.07.010

[6] Kaisare, Niket S., and Dionisios G. Vlachos. "A review on microcombustion: Fundamentals, devices and applications." Progress in Energy and Combustion Science 38, no. 3 (2012): 321-359. https://doi.org/10.1016/i.pecs.2012.01.001

[7] Karagiannidis, Symeon, John Mantzaras, Gregory Jackson, and Konstantinos Boulouchos. "Hetero-/homogeneous combustion and stability maps in methane-fueled catalytic microreactors." Proceedings of the Combustion Institute 31, no. 2 (2007): 3309-3317. https://doi.org/10.1016/i.proci.2006.07.121

[8] Kutz, Myer. Mechanical Engineers Handbook Second Edition. USA: John Wiley \& Sons, 1998.

[9] Li, J., S. K. Chou, W. M. Yang, and Z. W. Li. "A numerical study on premixed micro-combustion of CH4-air mixture: Effects of combustor size, geometry and boundary conditions on flame temperature." Chemical Engineering Journal 150, no. 1 (2009): 213-222. https://doi.org/10.1016/i.cej.2009.02.015

[10] Ma, Lun, Hao Xu, Xiaoting Wang, Qingyan Fang, Cheng Zhang, and Gang Chen. "A novel flame-anchorage microcombustor: Effects of flame holder shape and height on premixed $\mathrm{CH} 4$ /air flame blow-off limit." Applied Thermal Engineering 158 (2019): 113836. https://doi.org/10.1016/i.applthermaleng.2019.113836

[11] Maruta, Kaoru. "Micro and mesoscale combustion." Proceedings of the Combustion Institute 33, no. 1 (2011): 125150.

https://doi.org/10.1016/j.proci.2010.09.005 
[12] Miesse, Craig M., Richard I. Masel, Craig D. Jensen, Mark A. Shannon, and Mark Short. "Submillimeter-scale combustion." AlChE Journal 50, no. 12 (2004): 3206-3214.

https://doi.org/10.1002/aic.10271

[13] Munir, Fudhail Abdul, and Masato Mikami. "Modeling of Propane-air Combustion in Meso-scale Tubes with Wire Mesh." In 10th Asia Pacific Conference on Combustion (ASPACC 2015). Beijing China. 2015. https://doi.org/10.1299/jtst.2015jtst0008

[14] Munir, Fudhail Abdul, Masato Mikami, Muhammad Zahir Hassan, and Mohd Azli Salim. "Flame stabilization in multiple inlet channel meso-scale tube combustors with wire mesh." Journal of Advanced Vehicle System 4, no. 1 (2017): 20-27.

[15] Abdul Munir, Fudhail, Takehiko Seo, and Masato Mikami. "Optimization Of Flame Stabilization Limits In Meso-Scale Tube Combustors With Wire Mesh." International Journal of Mechanical \& Mechatronics Engineering IJMME-IJENS 17 (2017): 186-192.

[16] Norton, Dan G., and Dionisios G. Vlachos. "Combustion characteristics and flame stability at the microscale: a CFD study of premixed methane/air mixtures." Chemical Engineering Science 58, no. 21 (2003): 4871-4882.

https://doi.org/10.1016/i.ces.2002.12.005

[17] Norton, Dan G., and Dionisios G. Vlachos. "A CFD study of propane/air microflame stability." Combustion and Flame 138, no. 1-2 (2004): 97-107. https://doi.org/10.1016/i.combustflame.2004.04.004

[18] Tang, Aikun, Tao Cai, Jiang Deng, Yiming $\mathrm{Xu}$, and Jianfeng Pan. "Experimental investigation on combustion characteristics of premixed propane/air in a micro-planar heat recirculation combustor." Energy Conversion and Management 152 (2017): 65-71. https://doi.org/10.1016/i.enconman.2017.09.011

[19] Tang, Aikun, Tao Cai, Qiuhan Huang, Jiang Deng, and Jianfeng Pan. "Numerical study on energy conversion performance of micro-thermophotovoltaic system adopting a heat recirculation micro-combustor." Fuel Processing Technology 180 (2018): 23-31. https://doi.org/10.1016/..fuproc.2018.07.034

[20] Tang, Aikun, Yiming Xu, Jianfeng Pan, Wenming Yang, Dongyue Jiang, and Qingbo Lu. "Combustion characteristics and performance evaluation of premixed methane/air with hydrogen addition in a micro-planar combustor." Chemical Engineering Science 131 (2015): 235-242. https://doi.org/10.1016/j.ces.2015.03.030

[21] Tang, Aikun, Yiming Xu, Chunxian Shan, Jianfeng Pan, and Yangxian Liu. "A comparative study on combustion characteristics of methane, propane and hydrogen fuels in a micro-combustor." International Journal of Hydrogen Energy 40, no. 46 (2015): 16587-16596. https://doi.org/10.1016/j.ijhydene.2015.09.101

[22] Wan, Jianlong, and Aiwu Fan. "Effect of solid material on the blow-off limit of CH4/air flames in a micro combustor with a plate flame holder and preheating channels." Energy Conversion and Management 101 (2015): 552-560. https://doi.org/10.1016/i.enconman.2015.06.010

[23] Wan, Jianlong, Aiwu Fan, and Hong Yao. "Effect of the length of a plate flame holder on flame blowout limit in a micro-combustor with preheating channels." Combustion and Flame 170 (2016): 53-62. https://doi.org/10.1016/i.combustflame.2016.05.015

[24] Yuliati, Lilis. "Flame stability and behavior inside meso-scale combustor with different flame holder." In MATEC Web of Conferences, vol. 159, p. 02011. EDP Sciences, 2018. https://doi.org/10.1051/matecconf/201815902011 